\title{
Ethnicity capital and nation-building
}

\section{Hyginus Obinna Ogbonna}

Department of Sociology and Anthropology, Faculty of Social Sciences, University of Benin, Benin City, Nigeria.

Accepted 11 May, 2018

\begin{abstract}
This paper investigates 'Ethnicity Capital and Nation-building'. Its objectives are to examine the various ways by which ethnicity capital could be harnessed as a productive instrument for nation building, and to identify other dysfunctional consequences of ethnicity capital apart from being a productive instrument for nation building as well as to propose policy-based recommendations towards harnessing ethnicity capital as a necessary tool for nation building. To achieve these tasks, the paper reviewed the concept of ethnicity capital as a tool for nation building, investigating further its antinomies in a praxis situation (Nigerian situation); it adopted a comparative analysis on U.S and Nigeria to gain more insight on how a multi-ethnic nationality can thrive without conflicts in spite of ethnic divergence as well delineating preconditions for the process of nation building in a multi-ethnic society. The method used was purely descriptive. The paper reviewed a few relevant theoretical orientations, namely the Functionalist Theory and Robert K. Merton nuanced Functionalist perspective. The major findings include: Ethnicity capital could function as a productive instrument for nation building in various ways; a few of these ways include: it promotes national consciousness and national integration; it provokes a common political culture that incorporates the divergent groups. The findings also reveal that ethnicity capital could be a destructive force that pulls down the process of nation building as it is conflict-oriented if not positively harnessed etc. The paper therefore recommended thus: that political leadership should discountenance feelings of ethnic affiliations in governance and embrace the interest of all; inter-ethnic group languages to be introduced in schools for adoption by students to promote cultural tolerance and national consciousness; government to proscribe all so called democratic movements that promote ethnic consciousness rather than national consciousness and encourage movements that are nationally oriented etc.
\end{abstract}

Keywords: Ethnicity, capital, nation, nation-building.

Email: hygieobisons@yahoo.com. Tel: +2348033894208.

\section{INTRODUCTION}

Should ethnicity be harnessed as a tool for nationbuilding by political players and statesmen, it could no doubt become 'resources' for national greatness (Omotosho, 2016).

In proper epistemic articulation, the twin concepts of Ethnicity Capital and Nation-building suggest, utilizing or harnessing the concept of ethnicity as a tool or instrument for nation building. In broader terms; that is, employing ethnicity as an advantage or resources and/or asset (capital) for nation building rather than as an instrument of conflict or competition. Its underlying import shares nexus with the popular antithetical aphorism that says, "United, we stand but Divided, we fall"!

As Omotosho (2016) noted, one of the keys to understanding Nigeria's pluralistic society is the concept of Ethnicity. Ethnicity refers to political agitations or competitions due to ethnic rivalry, exploitation and control over resources among varying ethnic groups in a state (Omotosho, 2016). It also connotes the process of interactions or relations based on ethnic or racial affiliations.

Ethnicity distinguishes groupings of people who for historical reasons have come to be seen as distinctive by themselves and others - on the basis of location, origins and series of other cultural markers (Omotosho, 2016). However, defining ethnicity is almost an uphill task. This is because many scholars and theorists have come up with nuanced opinions and versions as to what 
the concept constitute. As Omotosho (2016) observed, while some scholars view the concept from the conflict and war-related angles, some have defined it from the angle of politicization of tribal configurations which involves power struggle and ethnic chauvinism. Besides, some scholars have carefully explained the concept from a "resource" (instrumental or capital) view point, suggesting that ethnicity ought to be an instrument of unity and national loyalty (Omotosho, 2016). To be sure, this later view point, ideal-typically forms the basis for the raison d'etre of this discourse on ethnicity capital and nation-building. Thus, with this thought process, it becomes ideal to think of ethnicity not only in terms of conflictive or competitive relations but also in the context of co-operation for national advantage.

Nation-building, on the other hand, involves efforts made by the statesmen and women in the harnessing of human, psychological and material resources that a nation or state possesses to put in place an organized structural system in the forms of institutions, agencies and crafts; all of which are channeled towards the development process of the state for the realization of a united society that delivers to its members a good quality and fulfilling life. Thus, the work of nation-building is therefore that of all members of that nation, but directed by those in positions of authority. If the ruling class gets it right, that is a national advantage; if otherwise, there is an element of distortion, and this is typical of nations that are overrun by ethnic conflicts and wars - like Nigerian civil war (1967 to 1970). Ethnic conflicts have precipitated wars and civil unrest in many African countries like Central African Republic, South Sudan, Rwanda and Burundi (Bozeman and Glickman, 1996; Osinubi and Oladipupo, 2006; Akapule, 2008; Wanjala, 2015; Omotosho, 2016). To be sure, these ethnic conflicts spring up because in these nations (including Nigeria) ethnicity has been politicized and manipulated as a device for destruction instead of capital for growth. Typically, Nigeria as a nation is a constituent of several ethnic nationalities. There are over 250 ethnic groups in Nigeria, and the major ones are Yoruba, lbo and Hausa (The Nigerian Observer, 2014). These autonomous grouping that used to exist as one distinctive nation of their own became a child of circumstance of the 1914 amalgamation by Lord Lugard and were forced to live together for administrative convenience of the colonial master (Britain). This surely was consequential to intertribal agitations even up till these present times.

Initially, the various ethnic groupings (Yoruba, Hausa, lbo) were instrumental to nationalist movements. The ethnic cleavages were utilized as a positive force and as an anti-colonialist instrument for nationalist's advantage/capital in agitating for independence. For instance, the three main leaders of the ethnic groups: Sir Ahmadu Bello/Tafawa Balewa (for the North/Hausas), Chief Obafemi Awolowo/Samuel Akintola (for the West/Yorubas), and Dr. Nnamdi Azikiwe/Mike Okpara (for the East/lbos) united as one and dismantled colonial rule by 1960 obtaining independence for Nigeria. Here, ethnicity worked for them as a capital, a resource, an advantage and as an instrument towards selfdetermination rather than as an instrument of competition and conflict. And true to the saying, "United, they stood".

However, after independence, ethnic strife and divisive tendencies (arising from census results, fiscal policy, election results) laced the Nigerian politics: where the North (Hausas) believe that the business of governance of the entity called Nigeria is their "birth right", while the Ibos feel that they are marginalized in government business, and the Yorubas feel disgruntled (although, neutral most times). These ethnic wranglines have kicked off several military insurrections that had ethnic leanings in Nigeria; like the Major Kaduna Nzeogwu led coup (January 1966) presumed by the Northern elders/politicians as purely sectional and deliberately calculated to terminate the Northern hegemonic oligarchy rule under late Tafawa Balewa (Prime Minister); also a counter-coup by June 1966 to return power to the North and eliminate the lbo-led unitaristic military dictatorship of late General Aguiyi Ironsi ushering in the government of Lt. Col. Yakubu Gowon as the new head of state. This culminated in the secession of the lbos under their military leader Col. Odumegwu Ojukwu that resulted into a civil war (1967 to 1970). To be sure, this historic antecedent helps to trace the emergence and dynamics of ethnicity in Nigeria from the colonial era.

On the contrary, other countries like U.S.A that comprises many ethnic nationalities have a different story. The United States has racially and ethnically diverse population (U.S Census Bureau, 2000). The U.S census officially recognises 6 racial categories, namely : White Americans (75.1\%), Black/African American (12.3\%), Native American and Alaskan Natives (0.9\%), Asian American (3.6\%), Native Hawaiian and Other Pacific Islander $(0.1 \%)$; non-racial but ethnic groupings such as the Hispanics and Latino Americans (12.5\%) and non-Hispanic/Latino Americans (87.5\%). In spite of the diverse ethnic nationalities in the U. S, ethnic conflicts are relatively not popular among them. This is partly because in U.S multiculturalism is not allowed (Gladney, 1996) unlike in other multi-ethnic countries like Nigeria where there is cultural pluralism among the various ethnic groups. We shall later return to this in the main text.

Ultimately therefore, since Nigeria as a nation-state has been brought together under the influence of colonialism with differing ethnic nationalities (on the aegies of 1914 amalgamation), rather than see this union as "a marriage of inconvenience" laced with conflicts, sectionalism and marginalization, the political leadership should harness ethnicity as a capital for nation building. This is the bedrock of this paper and the thrust of its investigation.

In the light of the foregoing utterances, the ultimate intention here is to structure this paper in a robust manner, in such a way that it contributes to the 
understanding of the dynamics of ethnicity capital and nation building. Having that in mind, this paper is structured under the following rubrics: 1) Brief Statement of the Objectives of the paper; 2) Concepts Clarifications; 3). Literature Review on the Subject Matter; 4) Relevant Theoretical Orientation; 5) Discussion of Findings; 6). Recommendations and Conclusion.

\section{Statement of the objectives}

The general objective of this paper is to examine how ethnicity can be utilised as an advantage, instrument or capital for nation building or otherwise.

However, its specific objectives include:

1. To identify other dysfunctional consequences of ethnicity capital apart from being a productive instrument for nation building.

2. To propose policy-based recommendations towards harnessing ethnicity as a necessary tool or capital for nation building.

\section{Concepts clarifications}

Certain keywords as adumbrated under this rubric are preponderant in the process of the discourse; we shall like to clarify them for a proper understanding as used in the context of the subject matter.

\section{Ethnicity}

Ethnicity is a derivative of the term "Ethnic group". Ethnic group simply defined refers to a community or population made up of people who share a common cultural background or descent. Besides, it refers to a category of people who identify with each other based on similarities, such as common ancestral, language, social, cultural or national experiences (Oxford Dictionaries, 2013). As James and Garrick (2010) noted, ethnic group identity has a strong psychological or emotional component that divides the people of the world into opposing categories of "us" and "them".

Ethnicity therefore connotes the process of interactions or relations among people based on ethnic or racial affiliations. $\mathrm{NYCl}$ (2017) suggests that, it refers to the belief by members of a social group that they are culturally distinctive from outsiders (other ethnic group) based on their shared characteristics (culture, language, religion and traditions).

\section{Capital}

It refers to wealth in the form of money or other assets taken as a sign of financial strength of an individual or organization (WebFinance, 2017). It is synonymous to, assets, wealth, resources, means or wherewithal. However, in the context of the discourse, capital here is used in a social sense (that is, social capital); that is social assets, wealth or resources not in the sense of financial strength per se, but as relates to social relations that have productive benefits.

\section{Ethnicity capital}

The suffix, "Capital" to Ethnicity here is used in a social sense. Thus, ethnicity capital connotes utilizing ethnicity as an asset, as an instrument of productive benefits, as a means to a goal, as a resource etc. Hence, ethnicity capital in terms of nation building suggest, utilizing ethnicity as an asset or productive instrument for nation building.

\section{Nation}

The concept refers to a community of people whose members are bound together by a sense of solidarity, a common culture and national consciousness (Omotosho, 2016). A nation is not the same as nation-state. When a nation attains the status of Sovereignty, where it can regulate its own affairs without any form of interference (external or internal), then it is said to have reached the status of a 'nation-state'. In the context of the discourse, we shall regard a nation to mean, a social group or population of people characterized by a) national consciousness b) similar culture/tradition c) common settlement/geographical location.

\section{Nation building}

The concept refers to collective efforts of men and women bound together by common national consciousness in utilizing both human and non-human resources for the transformation and development of their nation.

\section{LITERATURE REVIEW}

Certainly, a unique topic of this nature, 'Ethnicity Capital and Nation-building', should attract corpus of literature from various sources for relevant epistemological deliberations on the subject matter. Having reviewed a few of the existing body of literature on the subject, and appreciated the various nuanced views and versions of the sources, I have been able to concoct peculiar strands of thoughts considered fit for a proper epistemic articulation of the subject matter. These strands of 
thoughts are structured under the following sub-headers: 1) Ethnicity capital as a tool for nation building; 2) The Antinomies of Ethnicity capital: Ethnicity as Praxis (the Nigerian situation); 3) Why U.S.A, a multi-ethnic nationality thrives without ethnic conflicts (A comparative analysis with Nigeria); 4) The preconditions for the process of nation building for a nation with multi-ethnic nationalities.

It is hoped that these thought processes would illuminate our understanding of the twin concepts of 'ethnicity capital and nation building' and contribute to the existing body of knowledge on the subject.

\section{Ethnicity capital as a tool for nation building}

"United we stand, Divided we fall".

- Aesop's Fables (Ancient Greece, 6th Century BC; adopted as United States political propaganda, World War II).

The task of nation building in societies has been a challenging one if not unwholesomely intractable due to ethnic feelings and promotion; most especially in modern nations that have circumstantially been mopped together from their distinctive nationalities just as it was experienced during the colonial rule in Africa and other Third World countries like Nigeria.

To be sure, ethnographers estimate Nigeria's component tribal groupings at 250 , with addition of other sub-tribal nationalities at 200 or more (Omotosho, 2016). Thus, this makes the country one of the most multi-ethnic nations in Africa with diverse cultural groups, having different tribal languages (and none adopted as lingua franca) - this partly makes the task of nation building in a multi-ethnic society like Nigeria herculean task; but nevertheless surmountable!

Thus, notwithstanding the challenge of its complex nature, there are many ways by which ethnicity can be utilised as a capital or asset or a productive instrument for nation building.

However, to be able to articulate the various ways by which ethnicity capital could be a veritable tool for nation building, we shall like to demonstrate this via the mediation of 'the Conception of a Nation and its Properties'.

\section{Concept of a nation and its properties - Articulating the instrumentality of ethnicity capital}

A nation is a community of people whose members are bound together (in a geographical location) by a sense of solidarity, a common culture and a common national consciousness. Thus, by definition the properties of a nation include: 1). National consciousness, 2) Similar culture and tradition, 3) Common settlement or geographical location.

On the other hand, nation building as a concept results from the activities and processes embarked upon by members of a given nation. It involves actions, thoughts and behaviors aimed at sustaining the attributes or properties of a nation (Omotosho, 2016). And this is achieved when all efforts by the stakeholders, materials and non-materials are channeled to the course of national development and cohesion, while putting aside issues of differences (Omotosho, 2016). Thus, any effort towards nation building must sustain the ideals or attributes of the concept of a nation.

Thus, gleaning from the backdrop of the foregoing conceptualization of a nation and the process of nation building, we therefore propose as follows in terms of the various ways by which ethnicity capital could be utilised as a tool for nation building:-

Proposal 1 - On the property of national consciousness: Ethnicity capital promotes national consciousness and national integration. This is because, as a result of the existence of diversity among the various ethnic groups, and with the imperative primacy of building a united one strong nation (as the attributes of a nation require), therefore a deliberate effort is made to integrate the various divergent groups into a national consciousness, on psycho-sociological level, where the members of the nation (like Nigeria) do not see themselves as "a Yoruba man", or as "a Hausa man" or as "an Ibo man" but as a Nigerian (Omotosho, 2016). Thus, everyone sees the nation as "our nation" and hence join hands in providing ideas/programs towards its development. As the saying goes, "United we stand...". Example of such efforts of integrating national consciousness is the inscription of "WAZOBIA" on our national currency (N50 note): where "WA" means "come" in Yoruba; "ZO", means "Come" in Hausa; and "BIA", means "come" in Igbo.

Proposal 2 - On the property of common culture: Ethnicity capital provokes efforts towards evolving a common political culture that can incorporate the various divergent groups without destroying their natural distinctiveness so as to give them a common political goal and culture (which a true nation requires) towards nation building. Properly speaking, this was the idea or philosophy behind the British amalgamation of the two distinct groups (North and South protectorates) in 1914; a deliberate effort was made by the British government to give them a common political culture (British modern system of government) in spite of their divergences for easy governance and to sustain such amalgam (union) as a true nation. And, ever since Nigeria's independence, a deliberate effort has been made till the present times to govern Nigeria with common political ideology or culture (e.g, federal character principle) so as to truly answer "One Nigeria" amidst ethnic divergence. 
Proposal 3 - On the property of common geographical location: Ethnicity capital helps to create a sense of 'psycho-geographical' belonging among Nigerians where any Nigerian citizen irrespective of one's ethnic background is free to travel and live in any part of the nation without molestation, with the understanding that Nigeria belongs to all of us. Thus, the Yoruba can live in Ibo land, and the Hausa can live in Yoruba land or lbo land, and the lbo can live in Yoruba or Hausa and vice versa. This explains why Nigerian cities today are a hub of many multi-ethnic dwellers. However, paradoxically, this 'psycho-geographical' sense of belonging has not yet been fully imbibed in our value system. This is because whenever any strife exist between one ethnic group and the other, a particular group would try to kill those not considered as "sons of the soil" and drive them out of their land. For Example, the incessant killings of the lbos in the Northern part of the country; also the banishment of Ibo business men who live and trade at Ladipo market of Lagos to their home land by the former governor of Lagos State, Babatunde Fashola, in 2013. Such acts are not only inhuman but infringe on the rights of the victims as free citizens of Nigeria who by true properties of a nation, in terms of 'psycho-geographical' sense of belonging can live in any part of Nigeria.

Thus, in these various ways as deliberated above (but not limited to those) ethnicity capital can be utilised as a tool or productive instrument for nation building if properly utilized by the political leadership and the people.

\section{The antinomies of ethnicity capital - Ethnicity as praxis (The Nigerian situation)}

"Paradoxically, emerging leaders in Africa and particularly Nigeria have harnessed this opportunity (ethnicity capital) for aggrandizement and political greed basically to achieving group's or tribal interests or to achieving oligarchic/cabal interests..." (Omotosho, 2016).

To be sure, our ultimate intention here is to demonstrate the paradoxes of ethnicity capital in nation building. That is, whereas, ideally, ethnicity capital if rightly utilised contributes positively to nation building, in reality it is also laced with contradictions that distort the process of nation building. The praxis situation in Nigeria reveals a distortion between "what is"(reality) and "what ought to be" (ideal situation). That is to say, in practice, there is a mismatch between the expectations of ethnicity capital (ideal situation) and the actual situation (reality) in Nigeria. Whereas the ideal consciousness should have been "Unity in diversity" (so that "we can stand") rather the real consciousness manifesting itself in Nigeria sociocultural milieu is "Division in diversity" (and we are falling apart) - albeit, latent but dominant as the "son of the soil" sentiments pervade Nigeria socio-structural processes and fans the embers of ethnic cleavages which is tantamount to crisis of Ethnicity Capital.

Corroborating this, Berman et al. (2014) observed that "ethnic identities are seen as an obstacle to democratic nation building and reform."

Perhaps, institutional approach should best capture the paradox of ethnicity capital in nation building. Thus, the key institutions identified here are, the political institution and educational institution.

Politically, in concrete historical terms, the multi-ethnic entity fused together as Nigeria is a child of circumstance of the amalgamation of the Northern and southern protectorates in 1914 (Colonialism) which formed the primordial basis of all existing ethnic conflicts and agitations in Nigeria today. Thus, the autonomous groupings that formerly existed as one distinctive nation of their own became fused into a group of nations that are forced to live together as a nation-state. Typically, the British Indirect rule system via their "Divide and rule" approach (as they showed more interest in northern region than in the other regions) has some obvious consequences: it formed the bedrock upon which Nigerian politics and ethnic struggle were nurtured. The situation was worsened by series of agitations for leadership at the center by individual tribal groupings especially among the three main ethnic groups (Hausa, Ibo and Yoruba) and their leaders in one part; and in other part, several issues of national question such as, the census results, fiscal policy, election results and federal character emerged that provoked grievances. The situation further engendered strife reproducing itself to the January 1966 military putsch led by Major Kaduna Chukwuma Nzeogwu, presumed by the Northern elders and politicians as purely sectional and deliberately orchestrated both to terminate the Northern hegemonic oligarchy rule of the then Prime Minister (Late Tafawa Balewa) and to eliminate by firing squad their Northern elders. Hence, by June 1966 a counter-coup was staged which returned power to the North and eliminated the lboled unitaristic-military dictatorship at the center under the late General Thomas Aguyi Ironsi, thus ushering in the administration of Lt. Col. Yakubu Gowon as the new head of state. The situation marked an era of turmoil and ethnic wars between the lbos in the East and the Hausa/Fulani at the center, culminating into several ethnic killings in the north. The lbos under their military leader Col. Odumegwu Ojukwu forcibly declared secession, which precipitated into civil war from 19671970. And the reason for this ethnic-related wars/conflicts is not far-fetched because, as Nwankwo (2015) noted, "political, ethno-religious, or social conflicts often spring from ideas, aspirations and interests expressed by a group of people or individuals under particular environmental condition" - an environmental condition of fusion of multi-ethnic groups that have divergent aspirations!

To be sure, the bit about this historic antecedence of ethnic-engendered conflicts and military insurrections is 
to demonstrate that ethnicity capital apart from being an asset or tool for nation building can as well be a destructive tool or a liability to the process of nation building. Such conflicts rather deplete the resources for nation building. Even presently, ethnic oriented strife and conflicts are still endemic in Nigerian polity, much so as the various ethnic groups have divergent views towards governance - for instance, the North holds the primordial belief that the act of ruling Nigeria is their "birth right" (a false consciousness engendered by the British divide and rule approach during colonialism); the lbos believe they have been marginalized in the act of governance; and the Yoruba are seen as often neutral and passive. These ethnic divergences have reproduced into the present IPOB agitations for Biafra independence, and other ethnic minorities, ljaw (Niger Delta militants) agitating for Niger Delta Republic so as to have authority over the oil resources which estimates for more than $70 \%$ of the nation's foreign reserves (Omotosho, 2016). And no nation can succeed in an atmosphere of conflicts and ethnic killings. Hence, it fulfills the popular adage, "United we stand, but divided we fall". Such ethnic conflicts tend to a situation of anomie where each ethnic group is at each other's throats, breeding both overt and covert wars; in fact the situation becomes tantamount to Yeats (1919) world of anarchy, where "the Falcon can no longer hear the Falconer; things fall apart; the center cannot hold; and mere anarchy is loosed upon the world... ".

Besides, our government (the political class/leadership) is making matters worse. Whereas the political class who have the mantles of leadership are expected by the people to bring everyone together and harness the ethnicity capital as instrument for nation building, due to their selfish sectarian and tribal interests, rather seem to create more cracks in the "ethnic-ridden cracked walls" by favoring their own tribes at the expense of other tribes when they assume the reins of power. For example, in the present government of Buhari, almost all the ministers are from the North while other ethnic groups/tribes are poorly represented.

Moreso, the so called democratic principle that emerged in the fourth Republic in 1999 (after the era of military rule) is not robust: it gave rise to ethnic-based democratic movements (rather than national based movements) like, 'Egbe Afenifere' (in the West /Yorubas), the 'Arewa' (in the North/Hausas) and 'Ohaneze Ndigbo '(in the East/lbos). In all intents and purposes, these so called democratic movements are fanning the embers of their divergent ethnic interests rather than national interest. And ironically, it eventually breeds divisive ethnical consciousness rather than national consciousness.

Furthermore, in terms of education the "One Nigeria" cliche is lip service. The so called federal character is not observed in most Nigerian educational institutions. Most Federal Universities in Nigeria during admission process first consider their indigenes where the school is situated; the "son of the soil" syndrome still pervades our educational institutions with attendant victimizations of those considered not to be part of "them" as regards their ethnic affiliations. The so called "Quota system" is tailored along ethnic lines. Even appointments to high positions in these citadels of learning are still considered on this ethnic based lines thus sacrificing merit at the altar of nepotism and ethnic feelings. Constitutionally, education is first of all citizens' inalienable right!

To a limited or greater extent, with the foregoing arguments, we have been able to demonstrate that whereas ethnicity capital could be utilised as an instrument of nation building; as well, due to its immanent contradictions ethnicity capital can also be a destructive tool against nation building.

At this juncture, we shall advance to the next task; that is, Why U. S. A a multi-ethnic nationality thrives without ethnic conflicts (a comparative analysis with Nigeria).

\section{Why U.S.A, a multi-ethnic nationality thrives without ethnic conflicts - a comparative analysis with Nigeria}

United States has a racially and ethnically diverse population (U.S Census Bureau, 2000) yet maintains cohesion in its society without any emergence of ethnic cleavages or conflicts. The reasons are not far-fetched, these include as follow:

- In the first place, U.S treats its ethnic groups as "cultural minorities" and never allows them to become a political power seeking for independence or control of territories (Gladney, 1996). Unlike in Nigeria where the various groups maintain the consciousness that they can break out any day when the event unfolds.

- U.S has the policy to help and assist her ethnic minorities under the principle of fundamental Human Rights and the rights of citizenship. This policy has helped in smoothing down racial and ethnic conflicts in the U.S (Gladney, 1996). Unlike in Nigeria where rights of citizens of equal access to government benefits or public utilities are down played, while sectional and tribal interests are being upheld. For example, the present Nigerian government appointed about $90 \%$ of his ministers from the Northern region while neglecting other regions.

- In U.S, a subjective value of homogeneity is considerably present. They grew from a strong sense of national unity and consciousness in spite of any factors of differences. Unlike in Nigeria where heterogeneous factor like different languages fuel the sentiments of disunity.

- U.S observes a sense of common origin and culture. Unlike in Nigeria where the various ethnic groups trace their origins differently and have diverse cultures.

- Ultimately, U.S has a common language (American English), both literate and non-literate understand and speak it. Unlike in Nigeria where there are different 
languages and dialects that creates more divisions than unity. Even the so called lingual franca (English language) is not spoken and understood by all citizens except among the enlightened or the educated.

\section{Preconditions for the process of nation building for a nation with multi-ethnic diversities}

For any nation with multi-ethnic diversities that tends to embark on the process of nation building, the following factors must be in place to enable a smooth process:

Creation of an integrating ideology: As long as members of a society perceive themselves primarily as members of a specific tribe or ethnic group, a common nation is difficult to develop (Jochen, 2002). Unifying ideology does not necessarily replace the previously developed or differing ethnic identities, but has to exist and to be strong enough to convince the members of the sub-group (sub national entities) that they also have something in common that is meaningful and important for their cohesion. Such an ideology should be a "nationalist" ideology, a "collective conscience"(a la Durkheim) where everyone has the same mindset of oneness in spite of ethnic differences. And the basis is that, "we are all citizens of one great nation ".

\section{Strong sense of national unity through constitutionalism: The doctrine of constitutionalism is a key aspect of the rule of law. It suggests that the constitution is strictly adhered to. That is, where the law stipulates that everyone is equal before the law, then everyone is treated equally no matter ones ethnic background. As Omotosho (2016) observed, nation building, in the midst of diverse ethnic nationalities, is achievable only when all the people irrespective of their tribal, political and religious affiliations are carried along in the governmental process directly or indirectly. Therefore, with the growing expectations of different ethnic groups and divergence of interests, it is imperative that the act of governance strictly adheres to the principles of constitutionalism and ideals of liberty. That is, an atmosphere where the rule of law prevails without prejudice and sectionalism.}

Democratic permissiveness: The ethos of democratic permissiveness suggest an all "inclusive" structure (Acemoglu and Robinson, 2012) where the interest of all is represented and not "extractive" representing a sectional interest. That is, the body politic (the state) in its reason for being should represent the interests of all citizens without favoring one ethnic group at the expense of others. It connotes the absence of "divide and rule" approach introduced by the colonial master (Britain) that pitted the various ethnic groups against one another. Thus, to the extent that a nation allows the ethos of democratic permissiveness to thrive, the extent that the process of nation building can be achieved amidst diversities.

Leadership question: Everything rises and falls on the leader. The way the political leadership handles the ethnicity issue will determine whether ethnicity would be used as a capital, a productive instrument for nation building or as a destructive force that pulls the nation down. The ideology and values of the leader matters, if the leader is one who is tribalistic or ethnocentric, then he would cause more harm and would utilize ethnicity capital as an instrument of competition; in such situation the process of nation building will be distorted.

\section{THEORETICAL ORIENTATION}

The ultimate intention here is to develop a relevant theoretical model that lends credence to the objectives and assumptions of the subject matter, and equally contributes a profound but critical understanding of the discourse, 'Ethnicity Capital and Nation building'. To achieve this purpose, two theories are herein adopted, namely: a) The functionalist theory, and b) Robert K. Merton's nuanced functionalist perspective.

\section{Functionalist theory}

From a functionalist perspective, society is regarded as a system (Haralambos, 1980). And as a system, it has interrelated parts (called the social institutions, e.g family, economic, political, education and religious institutions). The functions of these parts or institutions are understood in terms of their contributions to the maintenance of the social system (society). The various parts are interrelated with each other to the extent that what happens in one part affects other parts and the social system as a whole (that is, functional unity).

To the functionalists, the integration of the various parts with one another is largely based on "value consensus" (shared values among its members). Hence, if the major values of society are expressed in the various parts of the social structure, those parts will be integrated.

Besides, functionalists assume that a certain degree of order and stability are essential for the survival of society, and it is shared values among the members of society that guarantees order. This is because the shared values will form the basis of social unity (social solidarity) since individuals will seem to identify with those who share same values as themselves.

\section{Contextualising the theory to the subject matter}

Functionalist theory is very relevant in understanding the 
dynamics of ethnicity capital and nation building. From the import of its theorizing, it reveals Ethnicity capital as playing a positive function, contributing positively to the process of nation building. For example, it was because of the efforts of the various ethnic groups and their leaders who came together in the nationalist movements that Nigeria independence from Britain became a reality in 1960.

Besides, the theory via its postulate of 'value consensus' has confirmed our assumptions in this discourse that one of the key preconditions for nation building is integrating and promoting national consciousness and integration among members of the society. Additionally, the theory via its postulate of social order (by the means of shared values) has underscored how social order and stability could be possible, and ethnic conflicts avoided in a multi-ethnic Nigerian society (by integrating shared values of national consciousness ideology in Nigerian citizens).

However, its weakness lies on the fact that the theory only focuses on functions of the part to the whole and does not focus on their draw backs or dysfunctions. For example, ethnicity capital in as much as it is functional to nation building can as well have a manifest latent function of creating conflicts and unwholesome competition in society.

\section{Robert K. Merton's nuanced functionalist perspective}

The American Sociologist, Robert K. Merton in 1949 in his nuanced version of functionalism attempts to refine and develop functionalist analysis (Haralambos, 1980). Merton argues that the parts of society should be analysed in terms of their 'effects' or 'consequences' on society as a whole and on individuals and groups within the society.

Merton singles out three related assumptions of functionalists and question their utility. The first he called, postulate of the functional unity (which assumes that any part of the system is functional for maintenance of entire system): Merton argued that this is doubtful, and illustrated with religious pluralism; that in such a society religion would tend to breed disunity rather than function to unite.

Besides, in the postulate of 'universal functionalism'(which assumes that every part of society has a positive function). To Merton, such assumption is incorrect because any part of society can be functional, dysfunctional or non-functional. To Merton, persisting cultural forms have a net balance of functional consequences.

Additionally, in the postulate of indispensability (that assumes that certain institutions of Society are indispensable). To Merton, no part of society should be viewed as indispensable because they can be replaced by alternative institutions.

\section{Contextualising the Mertonian perspective on the subject matter}

Mertonian nuanced perspective on functionalism is quite significant in understanding the antinomies, contradictions or consequences of ethnicity capital. For instance, Merton's postulation that a part of society can be functional or dysfunctional or non-functional helps us to understand that ethnicity capital in as much as it can contribute positively to nation building can as well be consequential to nation building. Example, ethnic plurality or diversities (like religious plurality as Merton illustrated) can create disunity or conflicts rather than function to unite as it is evident in Nigeria today.

Moreso, Merton's postulation that no part of society is indispensable (but can be replaced by alternatives) is so true with the current clamor for 'ethnic cleansing' (total removal of ethnic groupings and replacing them with more homogeneous groups) by modern societies in contemporary times since 1990 (Lieberman, 2010).

However, Merton's weakness lies in the fact that he believes in functional autonomy (that is, the assumption that what happens in a part may not affect the whole); such assumption can only work for any entity that has no network of systems. Society is a network of interrelated systems hence whatever that happens in one system will affect the whole.

\section{DISCUSSION}

Pursuant to the objectives of this paper, and from our investigations so far, the following are the findings uncovered:

1. Ethnicity capital can be a productive instrument for nation building: example, during pre-independence colonial era, the various ethnic groupings in their collective efforts of nationalist movements agitated for Nigeria independence and it became a reality in 1960 (Omotosho, 2016). Other ways by which ethnicity capital can be a productive instrument for nation building, include:

a) It promotes national consciousness and national integration.

b) Ethnicity capital provokes efforts towards evolving a common political culture that can incorporate the various divergent groups.

c) It creates a sense of 'psycho-geographical' belonging where any citizen is free to live in any part of the nation with the understanding that Nigeria belongs to all of us.

2. Ethnicity capital apart from being a productive instrument for nation building can also be dysfunctional to nation building (ala, Merton): example, in our investigation it was discovered that shortly after 
independence in 1960, conflicts and wars started arising in Nigeria due to ethnic cleavages and feelings (e.g., all the military insurrections since 1966 in Nigeria chequered history are tailored along ethnic group agitations, Omotosho, 2016).

3. The findings also reveal that U.S.A, a multi-ethnic nationality thrives without ethnic conflicts because as a policy it does not allow multiculturalism, has common language, has strong sense of national consciousness and enshrines as part of her policy to protect the rights of and help the ethnic minorities.

4. Finally, the findings reveal that if any multi-ethnic nation like Nigeria desires the process of nation building, it must meet certain preconditions like, creation of an integrating ideology for national consciousness; strong sense of national unity via constitutionalism; embrace democratic permissiveness and good leadership.

\section{RECOMMENDATIONS AND CONCLUSION}

Ethnicity capital is like a two-edged sword. It can be a productive instrument for nation building, and can as well be a destructive force that pulls down efforts in the process of nation building. Whether the concept of ethnicity capital serves as a productive instrument or a destructive force depends on the wisdom and intentions of the player (be they individuals or groups or political leadership). Thus, for any multi-ethnic nation that desires to move forward in the process of nation building, it will no doubt choose to harness ethnicity as a capital, a productive instrument towards nation building. To achieve this, the concerted effort of all is required, and the political leadership should spear head these efforts.

As a guide for line of actions towards achieving a positive process of nation building in a multi-ethnic society like Nigeria, a few policy-based recommendations are hereby proffered as follows:

1. Our political leadership (the political class) should discountenance personal interest, sectional interest and feelings of ethnic affiliations in governance. They should see themselves as representing the generality of the interest of the entire citizenry and not interest of a select few.

2. Political appointments should be based on merit and not based on ethnic affiliations or so called "son of the soil" syndrome.

3. More programs that encourage national consciousness should be created (NYSC is one of such programs: posting of corpers should be inter-tribal geographical posting to promote cultural tolerance and national consciousness).

4. Government should proscribe the so called democratic movements in the likes of Arewa, Afenifere and Ohaneze Ndi Igbo etc as such movements caused their members to think ethnically rather than think nationally, hence prone to ethnic cleavages and conflicts : movements that promote national consciousness, and not tribal consciousness, should be allowed to exist.

5. Government should give a listening ear to any ethnic group that feels marginalised and mitigate their grievances.

6. Inter-ethnic languages should be introduced in our primary/secondary schools curriculum for language adoption. That is, a student should study one of the ethnic group's languages other than one's own tribal language. This will integrate the sense of oneness and promote national consciousness required in nation building.

It is hoped that if these proposals (though not absolute) are adopted, ethnicity capital would be harnessed as a productive instrument for nation building.

\section{REFERENCES}

Acemoglu, D., and Robinson, J. (2012): Why Nations Fail: The Origins of Power, Prosperity and Poverty. U.S.A: Crown Business.

Akapule, S. A. (2008). Ethnic Conflict In Africa - The Need To Search For Remedies. www.modernghana.com.

Berman, B., Kymlicka, W., and Eyoh, D. (2004). Ethnicity and Democracy in Africa. Ohio University Press.

Bozeman, A. B., and Glickman, H. (1996). Conflicts in Africa; Ethnic Conflicts and Democratization in Africa. Foreign Affairs. July/August Issue. www.foreignaffairs.com.

Gladney, D. C. (1996). Relational Alterity. History and Anthropology, $9(4): 445-477$.

Haralambos, M. (1980): Sociology: Themes and Perspectives. Britain: University Tutorial Press.

James, P., and Garrick, B. (2010). Humanity - An Introduction to Cultural Anthropology (9th ed). Wadsworth Cengage.

Jochen, H. (2002). Nation-building in the Globalization process - A Contribution to Regional stability and Global security? SEFSymposium. University of Bonn.

Lieberman, B. (2010). Ethnic Cleansing verses Genocide. www.oxfordhandbooks.com.

Nwankwo, B. O. (2015). Rhetorics and realities of managing ethnoreligious conflicts: The Nigerian experience. American Journal of Educational Research, 3(3): 292-300.

NYCl (2017). Ethnicity and Ethnic Group - An explanation of these terms. Dublin: National Youth Council of Ireland.

Omotosho, O. F. (2016). Ethnicity as a tool for nation building in Nigeria. Journal of Basic and Applied Research International, 19(3): 175-193.

Osinubi, T. S., and Oladipupo, S. O. (2006). Ethnic conflicts in contemporary Africa: The Nigerian experience. Journal of Social Sciences, 12(2): 101-114.

Oxford Dictionaries (2013). Ethnicity: Definition of Ethnicity. England: Oxford University Press.

The Nigerian Observer (2014). The Problem of Ethnicity in Nigeria. April, 19th.

U.S Census Bureau (2000). Our Diverse Population: Race and Hispanic Origin.

Wanjala, S. N. (2015). The Roots of Ethnic Conflict in Africa: From Grievance to Violence. New York: Palgrave Macmillan.

WebFinance (2017). The Concept of Capital. www.businessdictionary .com.

Citation: Ogbonna, H. O. (2018). Ethnicity capital and nationbuilding. Net Journal of Social Sciences, 6(1): 9-17. 